\title{
Rs4612666 Polymorphism of the NLRP3 Gene Is Associated with the Occurrence of Large Artery Atherosclerotic Ischemic Strokes and Microembolic Signals
}

\author{
Lufeng Cheng, Ruihua Yin, Shaonan Yang, Xudong Pan (D), and Aijun Ma \\ Department of Neurology, The Affliated Hospital of Qingdao University, 59 Haier Road, Qingdao, Shandong 266000, China \\ Correspondence should be addressed to Xudong Pan; drpan022@163.com and Aijun Ma; maaijun.cn@163.com
}

Received 15 January 2018; Revised 11 March 2018; Accepted 15 March 2018; Published 23 April 2018

Academic Editor: Nobuo Kanazawa

Copyright (C) 2018 Lufeng Cheng et al. This is an open access article distributed under the Creative Commons Attribution License, which permits unrestricted use, distribution, and reproduction in any medium, provided the original work is properly cited.

\begin{abstract}
Purpose. Large artery atherosclerosis (LAA) ischemic stroke (IS) is the most common IS subtype, and microemboli are clinically important for indicating an increased risk of IS. Nucleotide-binding domain-like receptor protein 3 (NLRP3) plays a crucial role in the pathogenesis of atherosclerosis. The aim of this study is to investigate the relationship between NLRP3 gene polymorphisms and susceptibility for LAA IS and microembolic signals (MES) in the Chinese Han population. Methods. We studied 293 patients diagnosed with LAA IS and 265 controls. Transcranial Doppler (TCD) was used to monitor the MES in all of the patients. Depending on the presence or absence of MES, the patients were divided into MES-positive and MES-negative subgroups. PCR-RFLP or direct sequencing were used to analyze three NLRP3 gene polymorphisms. Results. Seventy-six patients presented with MES and the MESpositive rate was $25.94 \%$. Logistic regression analysis showed that the TT genotype frequency for the rs 4612666 gene polymorphism was higher in study patients than in the controls (adjusted $P=0.001$ ) and higher in MES-positive patients compared to MESnegative patients (adjusted $P=0.015$ ). The T allele of rs4612666 was associated with an increased risk for developing LAA IS and $\operatorname{MES}(P=0.001 ; P=0.015$, resp. $)$. Prevalence of the CCC haplotype was higher in the controls than in the patients $(P=0.009)$ and prevalence of the TGT haplotype was lower in the controls than in the patients $(P=0.019)$. Conclusions. The NLRP3 rs4612666 gene polymorphism may be related to the occurrence of LAA IS and MES, suggesting that the NLRP3 gene polymorphism increases the susceptibility of LAA IS by changing the plaque vulnerability.
\end{abstract}

\section{Introduction}

A systematic analysis for the Global Burden of Disease Study (GBD) 2015 reported that, among all of the neurological disorders analyzed, strokes account for the largest proportion of total global disability adjusted life-years (DALYS) (47.3\%) and deaths (67.3\%) [1]. Ischemic stroke (IS) accounts for $65 \%-80 \%$ of new increased stroke cases [2]. IS is believed to be a multifactorial disorder with many elements, including environmental and genetic factors associated with its pathogenesis [3]. According to the TOAST (Trial of ORG 10172 in Acute Stroke Treatment) system, large artery atherosclerosis (LAA) ischemic strokes are the most common stroke subtype [4] and are more likely to be influenced by genetic profiles [5]. Therefore, the study of gene polymorphisms and their relationship with LAA IS is of great importance for the prevention, diagnosis, and treatment of IS.

In recent years, the role that inflammation plays in atherosclerosis and its complications has drawn considerable attention [6]. The current understanding of the importance of inflammation during all phases of atherosclerosis, including formation, progression, and rupture of atherosclerotic plaques, has greatly increased [7]. In patients with large artery occlusive disease, active microemboli are released from the unstable atherosclerotic lesions and lead to acute cerebral infraction. Studies have shown that the presence of microembolic signals (MES) detected by transcranial Doppler ultrasound (TCD) is potential risk markers for IS and is a significant sign of instability in the atherosclerotic plaque [8]. 
The nucleotide-binding domain-like receptor protein 3 (NLRP3) inflammasome is the most well-understood inflammasome and plays an important role in the process of inflammation. The NLRP3 inflammasome is composed of NLRP3, the adaptor protein, apoptosis-associated speck-like protein (ASC), and proinflammatory caspase-1. Upon activation of NLRP3 by pathogen-associated molecular patterns (PAMPs) and damage-associated molecular patterns (DPMPs), NLRP3 assembles and leads to the excretion of mature proinflammatory cytokines, such as IL-1 $\beta$ and IL-18 [9]. Therefore, the NLRP3 inflammasome plays an important role in the inflammatory process of atherosclerosis. The NLRP3 gene was identified as the genetic locus for three dominantly inherited periodic fevers: familial cold autoinflammatory syndrome (FCAS), Muckle-Wells syndrome [10], and chronic infantile neurological cutaneous articular syndrome/neonatal onset multisystem inflammatory disease (CINCA/NOMID) [11]. These three diseases are collectively known as cryopyrinassociated periodic syndrome (CAPS), suggesting that the disease-associated variants of NLRP3 probably encode a hyperactive version of NLRP3 which promotes excessive production of IL-1 $\beta$ [12]. NLRP3 gene mutations are also observed to be associated with rheumatoid arthritis [13], Crohn's disease [14], and abdominal aortic aneurysms [15]. One study from China suggested that genetic polymorphisms in NLRP3 may influence the risk of ischemic stroke in the Chinese population [16]. To the best of our knowledge, there are limited studies regarding the relationship between NLRP3 polymorphisms and susceptibility for LAA stroke and MES in the Chinese Han population. Therefore, we performed transcranial Doppler emboli detection and genotyped the NLRP3 gene polymorphisms to investigate whether NLRP3 gene polymorphisms are associated with LAA stroke and MES.

\section{Materials and Methods}

2.1. Study Population. All recruited subjects were unrelated ethnic Han Chinese. We studied 293 patients who were diagnosed with LAA strokes according to the TOAST classification system [4] and had lesions that were limited to the internal carotid artery or middle cerebral artery regions. All patients were hospitalized in the Neurology Department of Affiliated Hospital of Qingdao University from January 2014 to December 2016. All patients were subjected to microemboli-monitoring. occurrence of MES, the patients were divided into MES-positive and MESnegative groups. Inclusion criteria for stroke patients were cerebral infarction confirmed by computer tomography (CT) or magnetic resonance (MR), cerebral vascular and cardiac lesions confirmed by TCD, cardiac ultrasound, brain magnetic resonance angiography (MRA), or whole brain digital subtraction angiography (DSA). Exclusion criteria were patients who were diagnosed with any other subtype of IS (cardioembolism, small-vessel occlusion, stroke of other determined etiology, and stroke of undetermined etiology) or had severe heart disease (recent myocardial infarction, angina pectoris disease, and valvular heart disease) and severe infection, severe liver and renal dysfunction, and cancer. Two hundred sixty-five controls were recruited from the Health
Examination Center. Inclusion criteria were the following: the subjects had no history of ischemic stroke, no cerebral infarction by brain CT or MRI, and no obvious atherosclerosis or angiostenosis by TCD, CTA, or MRA. Exclusion criteria were the same as the criteria used for the patient group.

The research was performed in accordance with the Code of Ethics of the World Medical Association (Declaration of Helsinki) for experiments involving human subjects. The study was permitted by the ethical committee of the Affiliated Hospital of Qingdao University (QDDXYXYFSXY-2014005). Informed consent was obtained from all participants.

2.2. Clinical Measurements and Laboratory Analysis. Collection of clinical data from the subjects was performed by welltrained investigators. Questionnaire surveys were conducted to investigate the general status of the subjects, including gender, age, history of hypertension, diabetes, coronary artery disease (CAD), history of smoking and drinking, BMI, and family history of cerebrocardiovascular events. Blood samples $(4 \mathrm{ml})$ were collected from the antecubital vein of all participants following an overnight fast and later added to EDTA tubes followed by a 10 -minute centrifugation at $3000 \mathrm{rpm}$. Levels of serum high sensitivity C-reactive protein (hs-CRP), total cholesterol (TC), triglycerides (TG), highdensity lipoproteins (HDL), low-density lipoproteins (LDL), and blood glucose (GLU) were measured in the laboratory of our hospital.

2.3. Genotyping the Polymorphisms. Genomic DNA was extracted from peripheral blood leukocytes using the TIANamp Blood DNA kit (Tiangen Biotech, Beijing, China) according to the manufacturer's instructions. Polymerase chain reaction and restriction fragment length polymorphism (PCR-RFLP) testing was used to investigate the NLRP3 rs4612666 and rs10754558 gene polymorphisms. Primers were designed and synthesized by Ruibiotech (Beijing, China). PCR amplifications were performed in a total reaction volume of $20 \mu \mathrm{l}$ that contained $2 \mu \mathrm{l}$ genomic DNA, $10 \mu \mathrm{l}$ 2XTaq MasterMix, $0.5 \mu \mathrm{l}$ of both forward and reverse primers $(10 \mu \mathrm{mol} / \mathrm{L})$, and $7 \mu \mathrm{l}$ double-distilled H2O. The PCR amplification conditions were as follows: initial denaturation at $95^{\circ} \mathrm{C}$ for $5 \mathrm{~min}$, followed by 30 cycles at $95^{\circ} \mathrm{C}$ for $30 \mathrm{~s}$, annealing at $57^{\circ} \mathrm{C}$ (or $58^{\circ} \mathrm{C}$ ) for $30 \mathrm{~s}$, and extension at $72^{\circ} \mathrm{C}$ for $30 \mathrm{~s}$ followed by a final extension step at $72^{\circ} \mathrm{C}$ for $7 \mathrm{~min}$. After PCR amplification, $3.5 \mu \mathrm{l}$ of PCR product was digested by restriction enzyme (New England Biolabs, Beijing, China) for $0.5 \mathrm{~h}$ at $37^{\circ} \mathrm{C}$ and subsequently evaluated by gel electrophoresis on a $2 \%$ agarose gel. Photographs (Figures 1 and 2) were taken using an automatic fluorescence/chemiluminescence imaging analysis system (Villber Luomat FX-X20 M). The rs7512998 genotype (Figure 3) was analyzed by direct sequencing (Ruibiotech, Beijing, China). The primer sequences and restriction enzymes are shown in Table 1.

2.4. Microembolic Signal Monitoring. TCD $($ EMS-9EB $\times 2 \mathrm{P}$ Doppler box/EMS-9EB multidrop $\times 4.2 \mathrm{MHz}$ probe) was used to monitor the MES in all patients within $72 \mathrm{~h}$ of stroke onset. The $2 \mathrm{MHz}$ probe was fixed to the patients' head, and the MES monitoring was performed in the initial segment 
TABLE 1: Primer sequence and restriction enzyme.

\begin{tabular}{|c|c|c|c|c|}
\hline SNP & $\begin{array}{l}\text { Primer sequence } \\
\qquad\left(5^{\prime} \rightarrow 3^{\prime}\right)\end{array}$ & $\begin{array}{c}\text { Annealing } \\
\text { temperature } \\
\left({ }^{\circ} \mathrm{C}\right) \\
\end{array}$ & $\begin{array}{l}\text { Restriction } \\
\text { enzyme }\end{array}$ & $\begin{array}{l}\text { Fragment length } \\
\text { (bp) }\end{array}$ \\
\hline rs4612666 & $\begin{array}{l}\text { F: TGCTTAAGGCCATTAATTGTG } \\
\text { R: CTCCACCATGGACAAGGAAG }\end{array}$ & 57 & BbsI & $\begin{array}{c}\text { TT: } 260 \\
\text { TC: } 260,102,105 \\
\text { CC: } 102,105\end{array}$ \\
\hline rs 10754558 & $\begin{array}{l}\text { F: CCGGGCATGGTGGCTCA } \\
\text { R: CCCCCGGCTGCACACTG }\end{array}$ & 58 & MboI & $\begin{array}{c}\text { GG: } 261 \\
\text { GC: } 261,236,25 \\
\text { CC: } 236,25\end{array}$ \\
\hline rs7512998 & $\begin{array}{l}\text { F: GTAACCACCATTCTATTTGC } \\
\text { R: CTGTTGGTGGGAAATGGTGC }\end{array}$ & 58 & $\begin{array}{c}\text { Direct } \\
\text { sequencing }\end{array}$ & \\
\hline
\end{tabular}

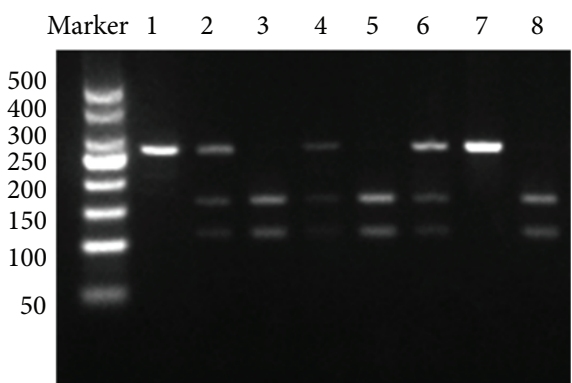

FIGURE 1: Agarose gel electrophoresis of the rs4612666 polymorphism. Line 1: TT; line 2: CT; line 3: CC; line 4: CT; line 5: CC; line 6: CT; line 7: TT; line 8: CC.

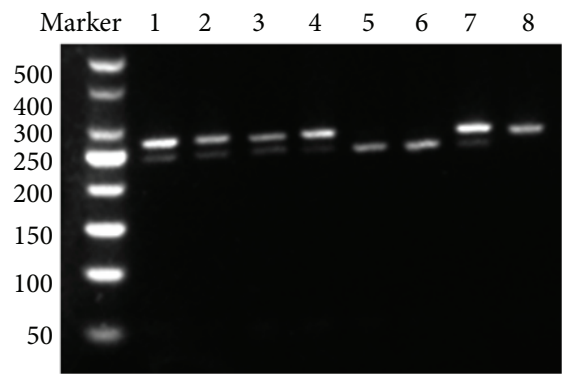

FIGURE 2: Agarose gel electrophoresis of the rs10754558 polymorphism. Line 1: CG; line 2: CG; line 3: CG; line 4: CG; line 5: CC; line 6: CC; line 7: CG; line 8: GG.

and distal segment of the symptomatic middle cerebral artery (MCA) (sampling depth, 50-65 $\mathrm{mm}$; distance between two points, $\geq 6 \mathrm{~cm}$; sample volume, $8-15 \mathrm{~cm}$; MES relative threshold, $\geq 5 \mathrm{~dB}$; and duration of microemboli-monitoring, $60 \mathrm{~min}$ ). Microemboli monitoring was performed by a system-trained professional and identified by two experienced neurology physicians. The criteria for microembolic signals [17] were (1) transient microembolic signal ( $<300 \mathrm{~ms})$; (2) high-intensity signal $(\geq 7 \mathrm{~dB}$ above the background signal); (3) being unidirectional within the Doppler velocity spectrum; (4) signals emerging randomly during the cardiac cycle; and (5) an audible sound (click, chirp, and whistle).

2.5. Statistical Analysis. Statistical analyses were performed using SPSS 20.0. We calculated allele frequencies and tested

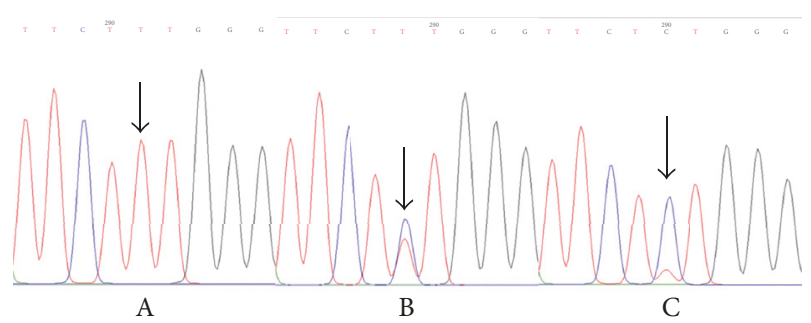

Figure 3: Sequencing of rs7512998. A: TT; B: CT; C: CC.

for agreement with the Hardy-Weinberg equilibrium using a Chi-square test for each locus. Continuous variables were shown as the mean \pm standard deviation (SD), and Student's $t$-test was used to analyze the differences. Categorical variables were presented as a frequency, and a Chi-square test was performed. Comparisons of genotype and allele frequencies were analyzed by Pearson's $\chi^{2}$ test or Fisher's exact test. Logistic regression analyses were used to calculate odds ratios (OR) with $95 \%$ confidential intervals (CI) after an adjustment with covariates. The SHEsis software platform was used for analyses of linkage disequilibrium (LD) and haplotype distributions $[18,19]$. A $P$ value of less than 0.05 was considered to be statistically significant.

\section{Results}

3.1. Clinical Characteristics of LAA and Control Groups. Table 2 shows the clinical characteristics of the LAA stroke patients and control subjects. There were no significant differences between the two cohorts in terms of age, history of CAD, BMI, and the levels of LDL $(P>0.05)$. The frequency of males, patients with hypertension and diabetes, smoking, alcohol drinking, family history of cerebrocardiovascular events, and the level of TGs, TC, LDL, hs-CRP, and GLU were higher in stroke groups than in control groups $(P<0.05)$. The HDL levels were lower in stroke groups compared to control groups $(P<0.05)$.

3.2. Association between NLRP3 Gene Polymorphisms and LAA Strokes. Genotype distributions did not deviate from the Hardy-Weinberg equilibrium in both groups $(P>0.05)$. When compared to the reference (CC), we observed that the TT genotype of rs4612666 was associated with a significantly 
TABLE 2: Clinical characteristics of LAA patients and control subjects.

\begin{tabular}{|c|c|c|c|}
\hline Variables & $\begin{array}{l}\text { LAA group } \\
\quad(n=293)\end{array}$ & $\begin{array}{l}\text { Control } \\
\text { group } \\
(n=265)\end{array}$ & $P$ value \\
\hline Age (years) & $62.89 \pm 12.58$ & $61.27 \pm 10.32$ & 0.097 \\
\hline Sex (man,\%) & $219(74.7 \%)$ & $150(56.6 \%)$ & $<0.001$ \\
\hline Hypertension $(n, \%)$ & $200(68.3 \%)$ & $122(46.0 \%)$ & $<0.001$ \\
\hline Diabetes $(n, \%)$ & $86(29.4 \%)$ & $46(17.4 \%)$ & 0.001 \\
\hline $\operatorname{CAD}(n, \%)$ & $68(23.2 \%)$ & $65(24.5 \%)$ & 0.715 \\
\hline Smoking $(n, \%)$ & $143(48.8 \%)$ & $54(20.4 \%)$ & $<0.001$ \\
\hline Drinking $(n, \%)$ & $121(41.3 \%)$ & $56(21.1 \%)$ & $<0.001$ \\
\hline $\begin{array}{l}\text { Family history of } \\
\text { cerebro-cardiovascular } \\
\text { events }(n, \%)\end{array}$ & $61(20.8 \%)$ & $19(7.2 \%)$ & $<0.001$ \\
\hline BMI $\left(\mathrm{kg} / \mathrm{m}^{2}\right)$ & $23.98 \pm 3.96$ & $23.87 \pm 3.73$ & 0.727 \\
\hline $\mathrm{TG}(\mathrm{mmol} / \mathrm{L})$ & $1.56 \pm 0.89$ & $1.79 \pm 1.09$ & 0.008 \\
\hline $\mathrm{TC}(\mathrm{mmol} / \mathrm{L})$ & $4.46 \pm 1.14$ & $4.80 \pm 0.98$ & $<0.001$ \\
\hline $\mathrm{HDL}(\mathrm{mmol} / \mathrm{L})$ & $1.05 \pm 2.33$ & $1.24 \pm 0.49$ & $<0.001$ \\
\hline $\mathrm{LDL}(\mathrm{mmol} / \mathrm{L})$ & $2.70 \pm 0.87$ & $2.60 \pm 0.69$ & 0.135 \\
\hline hs-CRP (mmol/L) & $7.58 \pm 9.46$ & $2.33 \pm 2.04$ & $<0.001$ \\
\hline GLU (mmol/L) & $6.27 \pm 2.51$ & $5.46 \pm 1.50$ & $<0.001$ \\
\hline
\end{tabular}

CAD: coronary artery disease; BMI: body mass index; TG: triglycerides; TC: total cholesterol; HDL: high-density lipoprotein; LDL: low-density lipoprotein; Hs-CRP: high-sensitivity C-reactive protein; GLU: fasting blood-glucose.

increased risk of LAA stroke after controlling for other covariates selected in our study (adjusted $\mathrm{OR}=3.021,95 \%$ CI 1.593-5.731, $P=0.001$ ). Furthermore, patients carrying the $\mathrm{T}$ allele showed an increased risk of stroke compared with carriers of the $\mathrm{C}$ allele $(\mathrm{OR}=1.506,95 \% \mathrm{CI} 1.188-1.909$, $P=0.001)$. However, the genotypes and allele frequencies for rs10754558 and rs7512998 were not significantly different between the two groups (Table 3).

3.3. Association between NLRP3 Gene Polymorphisms and Microembolic Signals. Seventy-six patients presented with microembolic signals in the LAA stroke group. There were no significant differences in the clinical characteristics between the MES-positive and MES-negative groups (Table 4). Logistic regression analysis showed that patients carrying the rs4612666 TT genotypes were at a significantly increased risk of microembolic signals (adjusted OR $=2.706,95 \%$ CI 1.210-6.048, $P=0.015$ ). Patients carrying the $\mathrm{T}$ allele were more likely to have microembolic signals $(\mathrm{OR}=1.593$, 95\% CI 1.095-2.315, $P=0.015)$. There was no association between microembolic signals and the rs10754558 or 7512998 genotypes (Table 5).

3.4. Haplotype Analysis. Using linkage disequilibrium (LD) test results, we conducted haplotype analyses for three SNPs using the SHEsis software platform (Figure 4). The results showed that frequency of the CCC haplotype in the control group was higher than in the LAA group and frequency of the TGT haplotype in the control group was lower than in the LAA group, indicating that the CCC haplotype may play

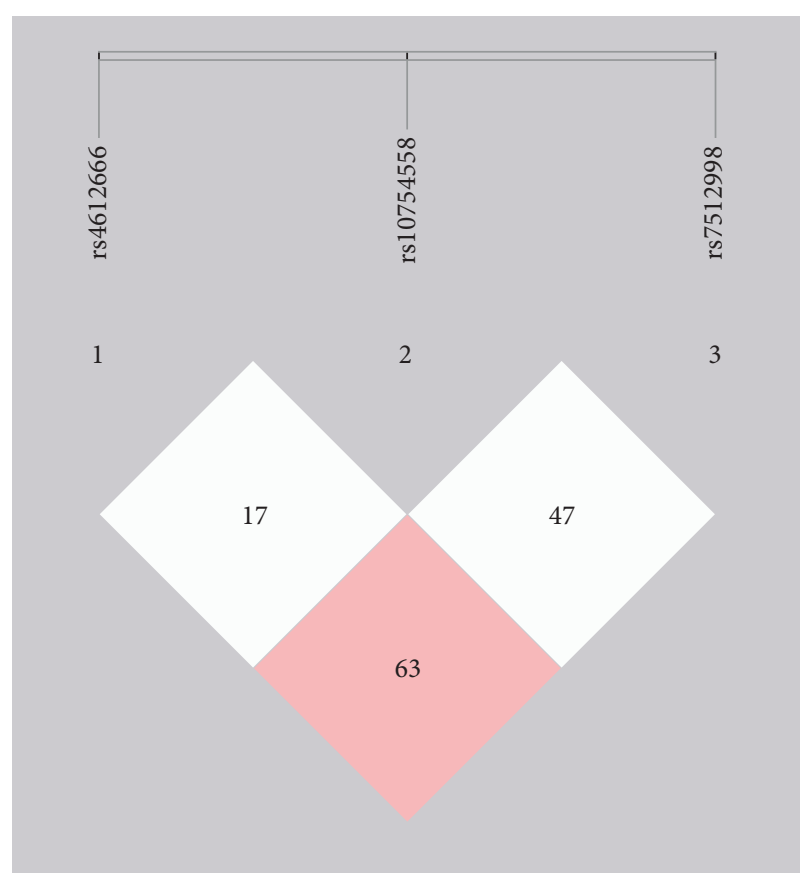

FIGURE 4: Linkage disequilibrium tests of rs4612666-rs10754558rs7512998: the $D^{\prime}$ value between rs4612666 and rs7512998 is 0.63 , the $D^{\prime \prime}$ value between rs10754558 and rs7512998 is 0.47 , and the $D^{\prime}$ value between rs4612666 and rs7512998 is 0.17 .

a protective role against LAA stroke and the TGT haplotype may have the opposite effect. (Table 6). 
TABLE 3: Genotype and allelic frequencies of NLRP3 SNPs in LAA patients and control subjects.

\begin{tabular}{|c|c|c|c|c|c|}
\hline SNP site & LAA group (\%) & Control group (\%) & $P$ value & Adjusted OR & $95 \% \mathrm{CI}$ \\
\hline \multicolumn{6}{|c|}{ rs4612666 } \\
\hline \multicolumn{6}{|c|}{ genotype } \\
\hline $\mathrm{CC}$ & $63(21.5 \%)$ & $93(35.1 \%)$ & - & 1 & \\
\hline $\mathrm{CT}$ & $163(55.6 \%)$ & $129(48.7 \%)$ & 0.090 & 1.531 & $0.935-2.505$ \\
\hline $\mathrm{TT}$ & $67(22.9 \%)$ & $43(16.2 \%)$ & 0.001 & 3.021 & $1.593-5.731$ \\
\hline \multicolumn{6}{|l|}{ allele } \\
\hline C & $289(49.3 \%)$ & $315(59.4 \%)$ & - & 1 & \\
\hline $\mathrm{T}$ & $297(50.7 \%)$ & $215(40.6 \%)$ & 0.001 & 1.506 & $1.188-1.909$ \\
\hline \multicolumn{6}{|c|}{ rs10754558 } \\
\hline \multicolumn{6}{|c|}{ genotype } \\
\hline $\mathrm{CC}$ & $73(24.9 \%)$ & $71(26.8 \%)$ & - & 1 & \\
\hline CG & $154(52.6 \%)$ & $131(49.4 \%)$ & 0.650 & 1.127 & $0.672-1.889$ \\
\hline GG & $66(22.5 \%)$ & $63(23.8 \%)$ & 0.538 & 1.184 & $0.648-2.163$ \\
\hline \multicolumn{6}{|l|}{ Allele } \\
\hline $\mathrm{C}$ & $300(51.2 \%)$ & $273(51.5 \%)$ & - & 1 & \\
\hline G & $286(48.8)$ & $258(48.5 \%)$ & 0.916 & 1.013 & $0.801-1.281$ \\
\hline \multicolumn{6}{|l|}{ rs7512998 } \\
\hline \multicolumn{6}{|l|}{ genotype } \\
\hline $\mathrm{CC}$ & $2(0.7 \%)$ & $3(1.1 \%)$ & - & 1 & \\
\hline $\mathrm{CT}$ & $45(15.4 \%)$ & $56(21.1 \%)$ & 0.492 & 2.275 & $0.218-23.768$ \\
\hline $\mathrm{TT}$ & $246(84.0 \%)$ & $206(77.7 \%)$ & 0.278 & 3.584 & $0.358-35.896$ \\
\hline \multicolumn{6}{|l|}{ allele } \\
\hline $\mathrm{C}$ & $49(8.4 \%)$ & $62(11.7 \%)$ & - & 1 & \\
\hline $\mathrm{T}$ & $537(91.6 \%)$ & $468(88.3 \%)$ & 0.063 & 1.452 & $0.978-2.154$ \\
\hline
\end{tabular}

TABLE 4: Clinical characteristics of MES(+) and MES(-) groups.

\begin{tabular}{|c|c|c|c|}
\hline variables & $\begin{array}{l}\operatorname{MES}(+) \\
(n=76)\end{array}$ & $\begin{array}{c}\operatorname{MES}(-) \\
(n=217)\end{array}$ & $P$ value \\
\hline Age (years) & $63.79 \pm 12.81$ & $62.58 \pm 12.51$ & 0.470 \\
\hline Sex (man, \%) & $55(72.4 \%)$ & $164(75.6 \%)$ & 0.580 \\
\hline Hypertension $(n, \%)$ & $46(60.5 \%)$ & $154(71.0 \%)$ & 0.092 \\
\hline Diabetes $(n, \%)$ & $21(27.6 \%)$ & $65(30.0 \%)$ & 0.702 \\
\hline $\mathrm{CAD}(n, \%)$ & $18(23.7 \%)$ & $50(23.0 \%)$ & 0.909 \\
\hline Smoking $(n, \%)$ & $36(47.4 \%)$ & $107(49.3 \%)$ & 0.771 \\
\hline Drinking $(n, \%)$ & $27(35.5 \%)$ & $94(43.3 \%)$ & 0.235 \\
\hline $\begin{array}{l}\text { Family history of } \\
\text { cerebrocardiovascular } \\
\text { events }(n, \%)\end{array}$ & $16(21.1 \%)$ & $45(20.7 \%)$ & 0.954 \\
\hline BMI $\left(\mathrm{kg} / \mathrm{m}^{2}\right)$ & $24.32 \pm 3.95$ & $23.87 \pm 3.96$ & 0.387 \\
\hline $\mathrm{TG}(\mathrm{mmol} / \mathrm{l})$ & $1.45 \pm 0.56$ & $1.60 \pm 0.98$ & 0.102 \\
\hline $\mathrm{TC}(\mathrm{mmol} / \mathrm{l})$ & $4.53 \pm 0.98$ & $4.44 \pm 1.19$ & 0.551 \\
\hline $\mathrm{HDL}(\mathrm{mmol} / \mathrm{L})$ & $1.04 \pm 0.25$ & $1.05 \pm 0.23$ & 0.644 \\
\hline $\mathrm{LDL}(\mathrm{mmol} / \mathrm{L})$ & $2.75 \pm 0.74$ & $2.68 \pm 0.91$ & 0.560 \\
\hline hs-CRP (mmol/L) & $7.51 \pm 10.22$ & $7.60 \pm 9.20$ & 0.946 \\
\hline GLU $(\mathrm{mmol} / \mathrm{L})$ & $6.19 \pm 2.70$ & $6.30 \pm 2.45$ & 0.746 \\
\hline
\end{tabular}


TABLE 5: Genotypes and allelic frequencies of NLRP3 SNPs in MES(+) and MES(-) groups.

\begin{tabular}{|c|c|c|c|c|c|}
\hline SNP site & $\begin{array}{c}\operatorname{MES}(+) \\
(\%)\end{array}$ & $\begin{array}{c}\operatorname{MES}(-) \\
(\%)\end{array}$ & $P$ value & OR & $95 \%$ CI \\
\hline \multicolumn{6}{|c|}{ rs4612666 } \\
\hline \multicolumn{6}{|c|}{ genotype } \\
\hline $\mathrm{CC}$ & $12(15.8 \%)$ & $51(23.5 \%)$ & - & 1 & \\
\hline $\mathrm{CT}$ & $38(50.0 \%)$ & $125(57.6 \%)$ & 0.464 & 1.314 & $0.633-2.730$ \\
\hline TT & $26(34.2 \%)$ & $41(18.9 \%)$ & 0.015 & 2.706 & $1.210-6.048$ \\
\hline \multicolumn{6}{|l|}{ allele } \\
\hline $\mathrm{C}$ & $62(40.8 \%)$ & $227(52.3 \%)$ & - & 1 & \\
\hline $\mathrm{T}$ & $90(59.2 \%)$ & $207(47.7 \%)$ & 0.015 & 1.593 & $1.095-2.315$ \\
\hline \multicolumn{6}{|c|}{ rs10754558 } \\
\hline \multicolumn{6}{|c|}{ genotype } \\
\hline $\mathrm{CC}$ & $18(23.7 \%)$ & $55(25.3 \%)$ & - & 1 & \\
\hline CG & $42(55.3 \%)$ & $112(51.6 \%)$ & 0.624 & 1.175 & $0.617-2.237$ \\
\hline GG & $16(21.1 \%)$ & $50(23.0 \%)$ & 0.841 & 1.084 & $0.494-2.378$ \\
\hline \multicolumn{6}{|l|}{ allele } \\
\hline $\mathrm{C}$ & $78(51.3 \%)$ & $222(51.2 \%)$ & - & 1 & \\
\hline G & $74(48.7 \%)$ & $212(48.8 \%)$ & 0.972 & 0.993 & $0.687-1.438$ \\
\hline \multicolumn{6}{|l|}{ rs7512998 } \\
\hline \multicolumn{6}{|l|}{ genotype } \\
\hline CC & $1(1.3 \%)$ & $1(0.5 \%)$ & - & 1 & \\
\hline $\mathrm{CT}$ & $15(19.75 \%)$ & $30(13.8 \%)$ & 0.521 & 0.388 & $0.022-6.999$ \\
\hline $\mathrm{TT}$ & $60(78.95 \%)$ & $186(85.7 \%)$ & 0.318 & 0.234 & $0.014-4.047$ \\
\hline \multicolumn{6}{|l|}{ allele } \\
\hline C & $17(11.2 \%)$ & $32(0.074)$ & - & 1 & \\
\hline $\mathrm{T}$ & $135(88.8 \%)$ & $402(0.926)$ & 0.144 & 0.632 & $0.340-1.175$ \\
\hline
\end{tabular}

TABLE 6: Haplotype analysis of rs4612666-rs10754558-rs7512998 in LAA patients and control subjects.

\begin{tabular}{|c|c|c|c|c|c|}
\hline haplotype & LAA group (freq) & Control group (freq) & $P$ value & OR & $95 \% \mathrm{CI}$ \\
\hline $\mathrm{C} \mathrm{C} \mathrm{C}$ & $26.52(0.045)$ & $44.38(0.084)$ & 0.009 & 0.521 & $0.317-0.856$ \\
\hline $\mathrm{C} \mathrm{C} \mathrm{T}$ & $98.42(0.168)$ & $95.45(0.180)$ & 0.620 & 0.924 & $0.677-1.262$ \\
\hline C G C & $7.81(0.013)$ & $15.02(0.028)$ & - & - & - \\
\hline $\mathrm{CG} \mathrm{T}$ & $156.24(0.267)$ & $160.15(0.302)$ & 0.205 & 0.844 & $0.649-1.097$ \\
\hline T C C & $11.15(0.019)$ & $0.08(0.000)$ & - & - & - \\
\hline T C T & $163.91(0.280)$ & $133.09(0.251)$ & 0.254 & 1.169 & $0.894-1.529$ \\
\hline T G C & $3.52(0.006)$ & $2.51(0.005)$ & - & - & - \\
\hline T G T & $118.42(0.202)$ & $79.31(0.150)$ & 0.019 & 1.453 & $1.062-1.988$ \\
\hline
\end{tabular}

All those frequencies $<0.03$ were ignored in analysis.

\section{Discussion}

Our study examining the relationship between SNPs of NLRP3 (rs4612666, rs10754558, and rs7512998) and LAA IS demonstrated that the frequency of the TT genotype and T allele of the NLRP3 rs4612666 polymorphism was considerably higher in the LAA group than in the control group, suggesting that the $\mathrm{T}$ allele may be associated with a susceptibility for LAA IS. However, the current study failed to demonstrate any influence that rs10754558 and rs7512998 may have on LAA IS.
NLRP3 is encoded by the NLRP3 gene, which is located on chromosome 1q44. There are more than 1000 SNPs in the human NLRP3 gene. Previous studies have shown that there is an association between NLRP3 gene polymorphisms and susceptibilities to certain diseases, including Crohn's disease [14], abdominal aortic aneurysms [15], and lateonset Alzheimer's disease [20]. The influence of an NLRP3 gene polymorphism on ischemic strokes was also shown in Zhu et al.s study [16]. LAA ischemic stroke is the most common type of ischemic stroke and is primarily caused by atherosclerosis. Over the past decade, we have demonstrated 
that inflammation plays a prominent role in atherosclerosis. The effect of the NLRP3 inflammasome cannot be ignored in the process of inflammation. Cholesterol crystals deposited in atherosclerotic lesions are likely essential intermediate steps in activating NLRP3 inflammation and leading to injury of the vascular wall. This mechanism involves both potassium efflux and translocation of lysosomal proteolytic contents [21, 22]. Duewell et al. [21] illustrated that mice with bone marrow-derived cells lacking NLRP3 inflammasome components were markedly resistant to the development of atherosclerosis. Recent studies have revealed involvement of the NLRP3 inflammasome in various human diseases, such as multiple sclerosis (MS) [23], gout [24], type 2 diabetes [25], and inflammatory bowel diseases [26]. This finding suggests that NLRP3 gene mutations may be related to the occurrence of different inflammatory diseases. Hitomi et al. [27] reported that there are significant associations between the human NLRP3 polymorphism rs4612666 and susceptibility to food-induced anaphylaxis and aspirin-induced asthma (AIA). The mechanism by which this occurs may be that the variant influences higher mRNA expression by altering expression enhancer activity or mRNA stability. One study by Zheng et al. [28] showed that there was no relationship between the rs 4612666 polymorphism and type 2 diabetes and insulin resistance. In a novel finding, this study has shown a significant relationship between the rs4612666 polymorphism and LAA ischemic stroke. Our study revealed that the TT genotype increases the risk of LAA ischemic stroke $(\mathrm{OR}=3.021)$, and the $\mathrm{T}$ allele is also an independent risk factor $(\mathrm{OR}=1.506)$. This suggests that the rs4612666 TT genotype and $\mathrm{T}$ allele are associated with a susceptibility for LAA strokes in the Chinese Han population. However, we did not perform any detailed experiments to investigate serum levels of the NLRP3 inflammasome, mRNA, IL18 , and IL-1 $\beta$. Therefore, the influence that rs4612666 has on NLRP3 inflammasome expression remains somewhat a mystery. Further studies investigating the mechanisms of NLRP3 gene polymorphisms on atherosclerosis are necessary.

Numerous studies have demonstrated the association between the NLRP3 rs10754558 polymorphism and a susceptibility for inflammatory diseases. Zhou et al. [16] reported that the G allele for NLRP3 rs10754558 was associated with an increased risk for ischemic stroke. Similarly, the $G$ allele has been reported to be correlated with CAD [29], type 2 diabetes [28], and food-induced anaphylaxis and aspirin-induced asthma [27]. However, one particular meta-analysis has suggested there is an association between the NLRP3 rs10754558 $\mathrm{C}$ allele and autoimmune and inflammatory diseases in the Latin American population but not the European and Asian ones [30]. The $\mathrm{C}$ allele seems to be protective against HIV1 infection [31]. The present study demonstrates that the NLRP3 rs10754558 gene polymorphism has no relationship to LAA strokes, differing from the results of Zhu et al. This finding may be observed because the polymorphism's allelic distribution varies with the ethnic origin of the studied population. There was also no ischemic stroke subtype division in Zhu et al.s study. There was limited investigation into NLRP3 rs7512998. Kunnas et al. [32] reported that the NLRP3 gene polymorphism rs7512998 C allele was associated with higher systolic and diastolic blood pressure in 50-year-old subjects. However, no relationship was found between rs7512998 and type 2 diabetes mellitus in a study by Wang et al. [33]. No significant association was found between rs7512998 and LAA strokes in our study. Additional linkage disequilibrium analysis and haplotype analysis suggested that the three SNPs were in incomplete linkage disequilibrium. The frequency of the CCC haplotype in the LAA group was significantly lower than in the control group and frequency of the TGT haplotype in the LAA group was higher than in the control group, suggesting that the CCC haplotype may play a protective role against LAA stroke and the TGT haplotype may have the opposite effect.

To investigate whether the NLRP3 gene polymorphism stabilizes atherosclerotic plaques, we used TCD to monitor MES in our patients. In our study, 76 patients presented with MES, which was a prevalence of $25.94 \%$. This was a lower prevalence than what was reported by Jiang and Iguchi et al. In a study by Jiang et al., 15 patients presented with MES out of 49 LAA patients who underwent microemboli-monitoring within $48 \mathrm{~h}$ of stroke onset. The MES rate for this study was $30.61 \%$ [34]. Iguchi et al. reported an MES-positive rate of $49 \%$ within $24 \mathrm{~h}$ of stroke onset [35]. The reason for our lower rate of MES may be because our microemboli-monitoring was performed within $72 \mathrm{~h}$ of stroke onset, and antiplatelet therapy was given to every patient before monitoring. It has been revealed that MES-positive rates can be reduced with antithrombotic therapy and longer periods of time between symptom onset and monitoring [36, 37]. Further analysis showed that patients carrying the $\mathrm{T}$ allele were more likely to have MES, demonstrating that the NLRP3 rs4612666 polymorphism was involved in the MES occurrence. This occurrence of microemboli may be due to two mechanisms: the rupture of atherosclerotic plaque contents into the blood stream, and the breaking off of a thrombus formed on an ulcerated surface or in the bloodstream [38]. MES indicates that the plaque is unstable. The break off of plaque is highly associated with inflammation. Varghese et al. reported that expression of NLRP3 mRNA was markedly higher in plaques of symptomatic patients than in asymptomatic patients, indicating that the activation of the NLRP3 inflammasome is related to plaque vulnerability. The NLRP3 gene variants changed the mRNA and expression levels of related inflammatory mediators [39]. Therefore, we hypothesize that the rs4612666 polymorphism leads to the destabilization of atherosclerotic plaque by accelerating inflammation in a lesion.

Our study indicates that the NLRP3 gene polymorphism rs4612666 may be associated with the occurrence of LAA ischemic strokes and MES in the Chinese Han population, suggesting that the NLRP3 gene polymorphism influences the susceptibility of LAA IS by changing plaque vulnerability. However, the present study contains a relatively low number of individuals, which may be a limitation. Additionally, there were only three gene polymorphism loci analyzed, which does not represent the entire gene. The replication of this research in different populations and additional in vivo analysis are required to completely elucidate the roles by which 
NLRP3 polymorphisms predispose for LAA strokes and MES.

\section{Conflicts of Interest}

The authors declare that they have no conflicts of interest.

\section{Acknowledgments}

This work was supported by the National Natural Science Foundation of China (no. 81571112 and no. 81641046), the Shandong Province Natural Science Foundation (2015GSF118172 and ZR2017BH012), and the Municipal Scientific and Technological Project of Qingdao City (15-9-2-86-nsh).

\section{References}

[1] V. L. Feigin, A. A. Abajobir, K. H. Abate et al., "Global, regional, and national burden of neurological disorders during 19902015: a systematic analysis for the global burden of disease study 2015," Lancet Neurology, vol. 16, no. 11, pp. 877-897, 2017.

[2] R. V. Krishnamurthi, V. L. Feigin, M. H. Forouzanfar et al., "Global and regional burden of first-ever ischaemic and haemorrhagic stroke during 1990-2010: findings from the Global Burden of Disease Study 2010," The Lancet Global Health, vol. 1, no. 5, pp. e259-e281, 2013.

[3] G. A. Donnan, M. Fisher, M. Macleod, and S. M. Davis, "Stroke," The Lancet, vol. 371, no. 9624, pp. 1612-1623, 2008.

[4] H. P. Adams Jr., B. H. Bendixen, L. J. Kappelle et al., "Classification of subtype of acute ischemic stroke: definitions for use in a multicenter clinical trial," Stroke, vol. 24, no. 1, pp. 35-41, 1993.

[5] S. Bevan, M. Traylor, P. Adib-Samii et al., "Genetic heritability of ischemic stroke and the contribution of previously reported candidate gene and genomewide associations," Stroke, vol. 43, no. 12, pp. 3161-3167, 2012.

[6] G. K. Hansson, "Inflammation and atherosclerosis: the end of a controversy," Circulation, vol. 136, no. 20, pp. 1875-1877, 2017.

[7] P. Libby, Y. Okamoto, V. Z. Rocha, and E. Folco, "Inflammation in atherosclerosis: transition from theory to practice," Circulation Journal, vol. 74, no. 2, pp. 213-220, 2010.

[8] Q. Hao, W. H. Leung, C. Leung et al., "The significance of microembolic signals and new cerebral infarcts on the progression of neurological deficit in acute stroke patients with large artery stenosis," Cerebrovascular Disease, vol. 29, no. 5, pp. 424-430, 2010.

[9] D. Y.-W. Fann, S.-Y. Lee, S. Manzanero, P. Chunduri, C. G. Sobey, and T. V. Arumugam, "Pathogenesis of acute stroke and the role of inflammasomes," Ageing Research Reviews, vol. 12, no. 4, pp. 941-966, 2013.

[10] H. M. Hoffman, J. L. Mueller, D. H. Broide, A. A. Wanderer, and R. D. Kolodner, "Mutation of a new gene encoding a putative pyrin-like protein causes familial cold autoinflammatory syndrome and Muckle-Wells syndrome," Nature Genetics, vol. 29, no. 3, pp. 301-305, 2001.

[11] J. Feldmann, A.-M. Prieur, P. Quartier et al., "Chronic infantile neurological cutaneous and articular syndrome is caused by mutations in CIAS1, a gene highly expressed in polymorphonuclear cells and chondrocytes," American Journal of Human Genetics, vol. 71, no. 1, pp. 198-203, 2002.

[12] J. P.-Y. Ting, S. B. Willingham, and D. T. Bergstralh, "NLRs at the intersection of cell death and immunity," Nature Reviews Immunology, vol. 8, no. 5, pp. 372-379, 2008.
[13] A. Kastbom, L. Ärlestig, and S. Rantapää-Dahlqvist, "Genetic variants of the NLRP3 inflammasome are associated with stroke in patients with rheumatoid arthritis," The Journal of Rheumatology, vol. 42, no. 10, pp. 1740-1745, 2015.

[14] A.-C. Villani, M. Lemire, G. Fortin et al., "Common variants in the NLRP3 region contribute to Crohn's disease susceptibility," Nature Genetics, vol. 41, no. 1, pp. 71-76, 2009.

[15] R. L. Roberts, A. M. van Rij, L. V. Phillips et al., "Interaction of the inflammasome genes CARD8 and NLRP3 in abdominal aortic aneurysms," Atherosclerosis, vol. 218, no. 1, pp. 123-126, 2011.

[16] Z. Zhu, J. Yan, C. Geng et al., "A polymorphism within the 3/UTR of NLRP3 is associated with susceptibility for ischemic stroke in Chinese population," Cellular and Molecular Neurobiology, vol. 36, no. 6, pp. 981-988, 2016.

[17] E. B. Ringelstein, D. W. Droste, V. L. Babikian et al., "Consensus on microembolus detection by TCD: international consensus group on microembolus detection," Stroke, vol. 29, no. 3, pp. 725-729, 1998.

[18] Y. Y. Shi and L. He, "SHEsis, a powerful software platform for analyses of linkage disequilibrium, haplotype construction, and genetic association at polymorphism loci," Cell Research, vol. 15, no. 2, pp. 97-98, 2005.

[19] Z. Li, Z. Zhang, Z. He et al., "A partition-ligation-combinationsubdivision em algorithm for haplotype inference with multiallelic markers: update of the SHEsis," Cell Research, vol. 19, no. 4, pp. 519-523, 2009, http://analysis.bio-x.cn.

[20] M.-S. Tan, J.-T. Yu, T. Jiang et al., "NLRP3 polymorphisms are associated with late-onset Alzheimer's disease in Han Chinese," Journal of Neuroimmunology, vol. 265, no. 1-2, pp. 91-95, 2013.

[21] P. Duewell, H. Kono, K. J. Rayner et al., "NLRP3 inflammasomes are required for atherogenesis and activated by cholesterol crystals," Nature, vol. 464, no. 7293, pp. 1357-1361, 2010.

[22] K. Rajamäki, J. Lappalainen, K. Öörni et al., "Cholesterol crystals activate the NLRP3 inflammasome in human macrophages: a novel link between cholesterol metabolism and inflammation," PLoS ONE, vol. 5, no. 7, Article ID el1765, 2010.

[23] M. Inoue and M. L. Shinohara, "NLRP3 inflammasome and MS/EAE”, Autoimmune Diseases, vol. 2013, Article ID 859145, 8 pages, 2013.

[24] F. Martinon, V. Pétrilli, A. Mayor, A. Tardivel, and J. Tschopp, "Gout-associated uric acid crystals activate the NALP3 inflammasome," Nature, vol. 440, no. 7081, pp. 237-241, 2006.

[25] H.-M. Lee, J.-J. Kim, H. J. Kim, M. Shong, B. J. Ku, and E.-K. Jo, "Upregulated NLRP3 inflammasome activation in patients with type 2 diabetes," Diabetes, vol. 62, no. 1, pp. 194-204, 2013.

[26] T. Strowig, J. Henao-Mejia, E. Elinav, and R. Flavell, "Inflammasomes in health and disease," Nature, vol. 481, no. 7381, pp. 278-286, 2012.

[27] Y. Hitomi, M. Ebisawa, M. Tomikawa et al., "Associations of functional NLRP3 polymorphisms with susceptibility to foodinduced anaphylaxis and aspirin-induced asthma," The Journal of Allergy and Clinical Immunology, vol. 124, no. 4, pp. 779.e6785.e6, 2009.

[28] Y. Zheng, D. Zhang, L. Zhang, M. Fu, Y. Zeng, and R. Russell, "Variants of NLRP3 gene are associated with insulin resistance in Chinese Han population with type-2 diabetes," Gene, vol. 530, no. 1, pp. 151-154, 2013.

[29] D. Zhou, X. Wang, T. Chen et al., “The NLRP3 rs10754558 polymorphism is associated with the occurrence and prognosis of coronary artery disease in the Chinese Han population," 
BioMed Research International, vol. 2016, Article ID 3185397, 9 pages, 2016.

[30] Y. H. Lee and S.-C. Bae, "Association between functional NLRP3 polymorphisms and susceptibility to autoimmune and inflammatory diseases: a meta-analysis," Lupus, vol. 25, no. 14, pp. 1558-1566, 2016.

[31] A. Pontillo, L. A. Brandão, R. L. Guimarães, L. Segat, E. Athanasakis, and S. Crovella, "A $3^{\prime}$ UTR SNP in NLRP3 gene is associated with susceptibility to HIV-1 infection," Journal of Acquired Immune Deficiency Syndromes, vol. 54, no. 3, pp. 236240, 2010.

[32] T. Kunnas, K. Määttä, and S. T. Nikkari, "NLR family pyrin domain containing 3 (NLRP3) inflammasome gene polymorphism rs7512998 $(\mathrm{C}>\mathrm{T})$ predicts aging-related increase of blood pressure, the TAMRISK study," Immunity \& Ageing, vol. 12, no. 1, Article ID 19, 2015.

[33] S. Wang, F. Fang, W. B. Jin, X. Wang, and X. S. Zheng, "Investigation into the association between NLRP3 gene polymorphisms and susceptibility to type 2 diabetes mellitus," Genetics and Molecular Research, vol. 14, no. 4, pp. 17447-17452, 2015.

[34] J. Jiang, Y. Jiang, S. Feng et al., "Microembolic signal monitoring of TOAST-classified cerebral infarction patients," Molecular Medicine Reports, vol. 8, no. 4, pp. 1135-1142, 2013.

[35] Y. Iguchi, K. Kimura, K. Kobayashi, S. Yamashita, K. Shibazaki, and T. Inoue, "Microembolic signals after 7 days but not within 24 hours of stroke onset should be predictor of stroke recurrence," Journal of the Neurological Sciences, vol. 263, no. 12, pp. 54-58, 2007.

[36] T. T. Idicula, H. Naess, and L. Thomassen, "Microemboli-monitoring during the acute phase of ischemic stroke: Is it worth the time?" BMC Neurology, vol. 10, Article ID 79, 2010.

[37] X. Wang, W. H. Lin, Y. D. Zhao et al., "The effectiveness of dual antiplatelet treatment in acute ischemic stroke patients with intracranial arterial stenosis: a subgroup analysis of CLAIR study," International Journal of Stroke, vol. 8, no. 8, pp. 663-668, 2013.

[38] M. P. Spencer, G. I. Thomas, S. C. Nicholls, and L. R. Sauvage, "Detection of middle cerebral artery emboli during carotid endarterectomy using transcranial doppler ultrasonography," Stroke, vol. 21, no. 3, pp. 415-423, 1990.

[39] G. P. Varghese, L. Folkersen, R. J. Strawbridge et al., "NLRP3 inflammasome expression and activation in human atherosclerosis," Journal of the American Heart Association, vol. 5, no. 5, 2016. 


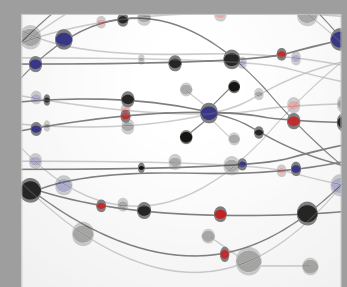

The Scientific World Journal
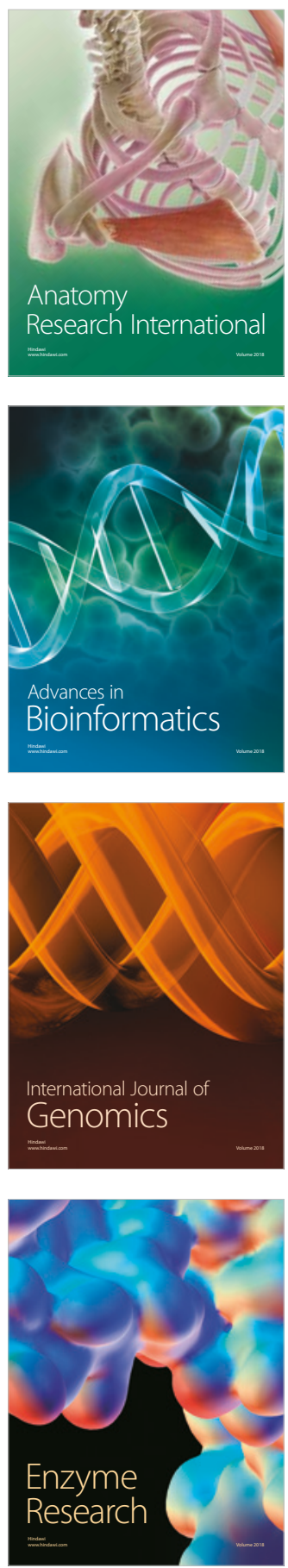
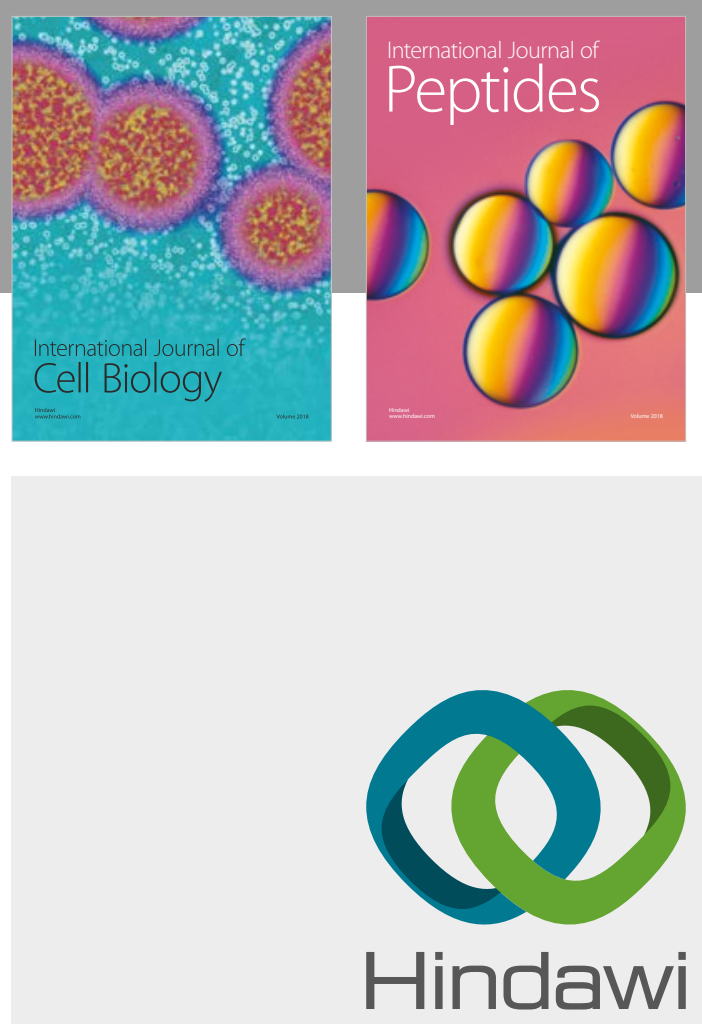

Submit your manuscripts at

www.hindawi.com
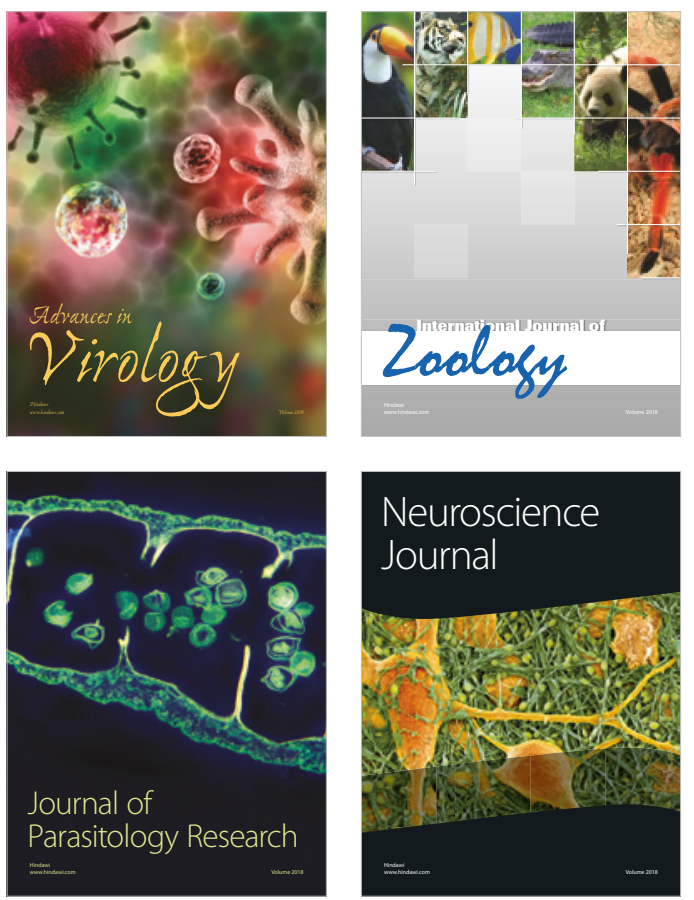
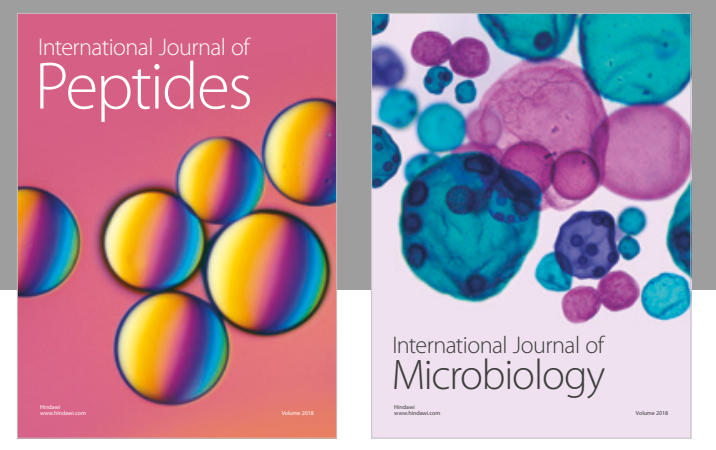

nternational Journal of Microbiology
Journal of
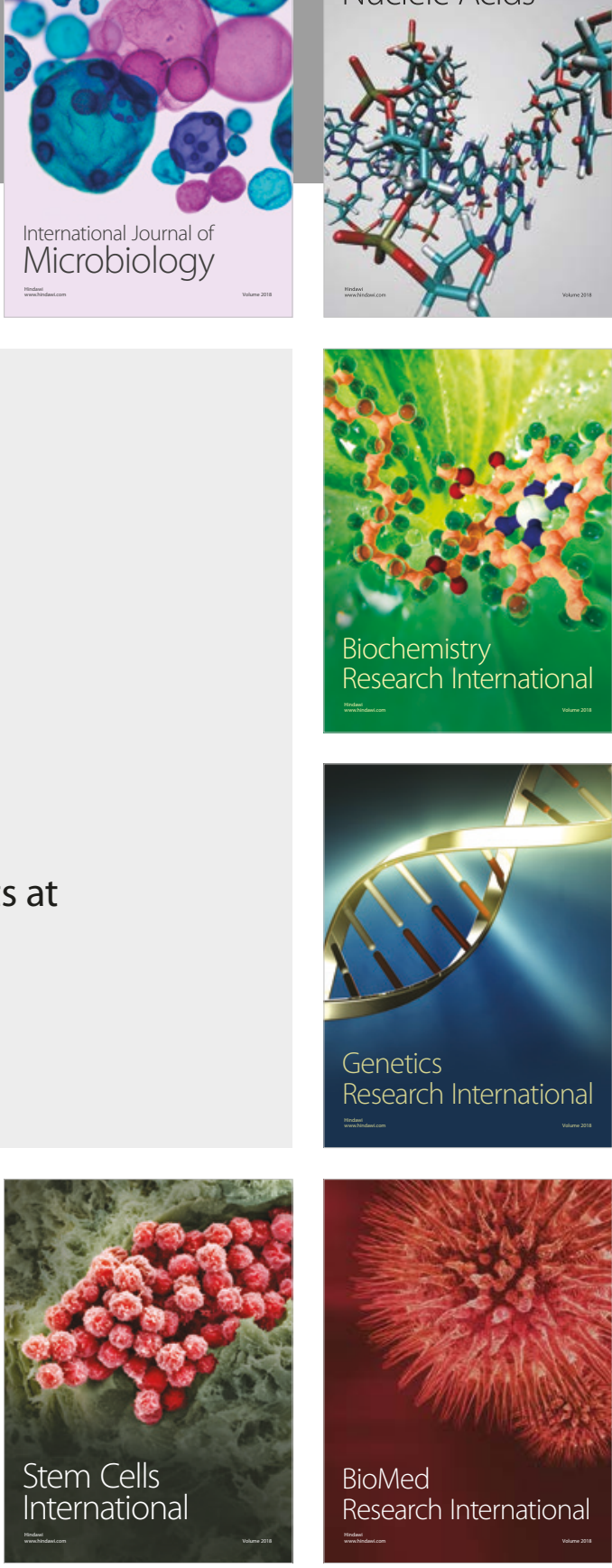
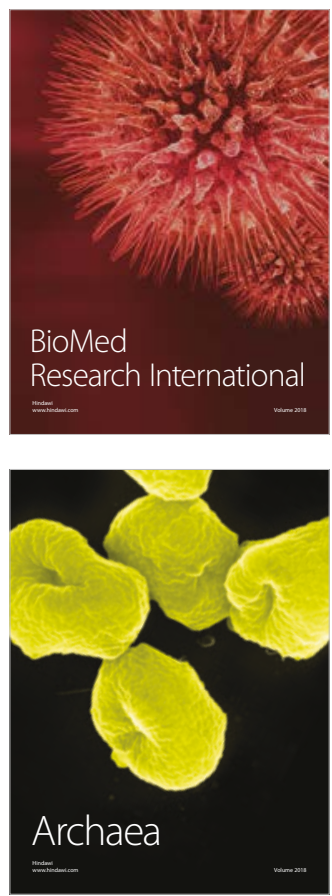